\title{
Efeito residual da adubação nitrogenada e inoculação de Azospirillum brasilense na cultura do milho
}

\section{Residual effect of nitrogen fertilization and Azospirillum brasilense inoculation in the maize culture}

\author{
Jaqueline Huzar Novakowiski ${ }^{1 *}$; Itacir Eloi Sandini²; Margarete Kimie Falbo ${ }^{3}$; \\ Aníbal de Moraes $^{4}$; Jackson Huzar Novakowiski ${ }^{1}$; Nicole Colombari Cheng ${ }^{1}$
}

\section{Resumo}

\begin{abstract}
A bactéria diazotrófica Azospirillum brasilense é um organismo capaz de fixar nitrogênio da atmosfera e produzir hormônios vegetais. No entanto, há carência de informações a respeito de seu uso em condições de campo, sobretudo em sistemas de produção que tem a presença de animais em um determinado período do ano. O objetivo do trabalho foi avaliar a associação do efeito residual da adubação nitrogenada na pastagem de inverno e a inoculação de $A$. brasilense na cultura do milho. Foram conduzidos dois experimentos em Guarapuava (PR) durante a safra 2008/09 com delineamento de blocos casualizados, com parcelas subdivididas, em três repetições. A parcela principal consistiu da aplicação de 5 doses de $\mathrm{N}\left(0,75,150,225\right.$ e $\left.300 \mathrm{~kg} \mathrm{ha}^{-1}\right)$ na pastagem de aveia preta e azevém ocupada por bovinos e 4 tratamentos no milho $\left(\mathrm{T} 1=\right.$ controle; $\mathrm{T} 2=$ inoculação de $A$. brasilense; $\mathrm{T} 3=75 \mathrm{~kg} \mathrm{ha}^{-1} \mathrm{de} \mathrm{N} ; \mathrm{T} 4=150$ $\mathrm{kg} \mathrm{ha}^{-1} \mathrm{de} \mathrm{N}$ ). Foram avaliados: população de plantas, espigas por planta, produtividade, massa de mil grãos, grãos ardidos, fileiras de grãos por espiga e grãos por fileira. Houve efeito residual do nitrogênio aplicado na pastagem sobre a cultura do milho. A massa de mil grãos e o número de fileiras por espiga de milho apresentaram resposta quadrática pelo aumento da dose de $\mathrm{N}$ na pastagem. A inoculação de $A$. brasilense proporcionou produtividade superior ao controle mesmo com o aumento da dose de $\mathrm{N}$ aplicada na pastagem, com resposta quadrática no experimento 1 e linear no experimento 2.
\end{abstract}

Palavras-chave: Zea mays L., bactérias diazotróficas, fixação biológica de nitrogênio, adubação nitrogenada

\begin{abstract}
The diazotrophic bacteria Azospirillum brasilense is an organism able to fix nitrogen of atmosphere and produce plant hormones. Nevertheless, there is lack of information with regard to use in field conditions, especially in production systems that have presence of animals in a determined year period. The objective of paper was to evaluate the association of the nitrogen residual effect of fertilization in pasture winter and the inoculation with $A$. brasilense in the maize culture. Were carried two experiments in Guarapuava (PR) in season 2008/09 with randomized block design with split plots in three replication. The main parcel consisted of application 5 levels of $\mathrm{N}\left(0,75,150,225\right.$ e $\left.300 \mathrm{~kg} \mathrm{ha}^{-1}\right)$ in pasture of black oat and ryegrass occupied by bovines and 4 treatments in the maize $(\mathrm{T} 1=$ control; $\mathrm{T} 2=$ inoculation
\end{abstract}

\footnotetext{
1 Acadêmicos do curso de Agronomia, Universidade Estadual do Centro-Oeste, UNICENTRO, Campus CEDETEG, Rua Camargo Varela de Sá, nº 3, Vila Carli, Guarapuava, PR, CEP 85.040-080. E-mail: jaquehuzar@hotmail.com; jacksonhuzar@hotmail. com; nicole9981@hotmail.com

2 Eng $^{\text {o }}$ Agr $^{\mathrm{o}}$, Prof. Dr. do Dept ${ }^{\circ}$ de Agronomia, UNICENTRO. E-mail: isandini@hotmail.com

3 Médica Veterinária, Prof ${ }^{a}$. Dr ${ }^{a}$. do Dept ${ }^{\circ}$ de Medicina Veterinária, UNICENTRO. E-mail: margaretefalbo@hotmail.com

${ }^{4}$ Eng $^{\mathrm{o}}$ Agr $^{\mathrm{o}}$, Prof. Dr. da UFPR, Dept ${ }^{\mathrm{o}}$ de Fitotecnia e Fitossanitarismo. E-mail: anibalm@ufpr.br

* Autor para correspondência
} 
of $A$. brasilense; $\mathrm{T} 3=75 \mathrm{~kg} \mathrm{ha}^{-1}$ of $\mathrm{N} ; \mathrm{T} 4=150 \mathrm{~kg} \mathrm{ha}^{-1}$ of $\mathrm{N}$ ). Were evaluated: plants population, ears per plant, productivity, mass thousand grains, damage grains, row per ear and grains per row. There was residual effect of nitrogen applied in the pasture on maize culture. The mass thousand grains and the number of rows per ear of maize presented quadratic response for increase of nitrogen level in the pasture. The inoculation of $A$. brasilense provided higher productivity than control same with increase the nitrogen level applied in the pasture, with quadratic response in the experiment 1 and linear in the experiment 2 .

Key words: Zea mays L., diazotrophic bacteria, nitrogen biological fixation, nitrogen fertilization

\section{Introdução}

A integração lavoura-pecuária (ILP), na região Centro-Sul do Paraná, é um sistema de produção que busca conciliar a máxima produção animal no período de inverno, e de grãos durante o verão. Nesse sistema, o milho (Zea mays L.) é uma das culturas com grande inserção, o que é decorrente de sua boa adaptabilidade à região de cultivo e alta demanda comercial. Para tanto, o manejo das pastagens de inverno é decisivo não somente para a obtenção de bons rendimentos zootécnicos, mas também para definir o potencial produtivo das culturas de verão, especialmente no sistema de plantio direto (NICOLOSO; LANZANOVA; LOVATO, 2006), e garantir a sustentabilidade do sistema.

Dentre as práticas de manejo, a adubação nitrogenada é um aspecto importante a ser considerado, pois a aplicação de nitrogênio $(\mathrm{N})$ na pastagem, além de proporcionar maior rendimento, permite a distribuição mais uniforme da forragem e um ciclo de produção maior (HERINGER; MOOJEN, 2002) e com aumento na produção animal (PARIS et al., 2009).

$\mathrm{Na}$ cultura do milho a adubação nitrogenada apresenta grande importância, pois, o $\mathrm{N}$ é um dos nutrientes que apresenta os efeitos mais relevantes no aumento da produção de grãos (FERNANDES; LIBARDI; TRIVELIN, 2008), uma vez que é requerido em grandes quantidades e além da clorofila, compõe substâncias como proteínas, enzimas e ácidos nucléicos. No entanto, os fertilizantes nitrogenados amplamente utilizados na agricultura moderna são oriundos de combustíveis fósseis que são fontes não renováveis, e como Cantarella (2007) relata, tais fertilizantes são um dos insumos mais caros do custo de produção da cultura do milho.

Assim, devido à crescente busca por sustentabilidade nos sistemas agrícolas de produção, alguns autores têm apresentado como forma alternativa para a economia de fertilizante nitrogenado, a fixação biológica de nitrogênio (FBN), a qual pode suplementar ou, até mesmo, substituir a utilização destes fertilizantes (REIS JÚNIOR et al., 1998; BERGAMASCHI, 2006).

A FBN é um processo de transformação do $\mathrm{N}_{2}$ na forma inorgânica combinada $\mathrm{NH}_{3}$, e a partir daí, em formas reativas orgânicas e inorgânicas. A reação de redução do $\mathrm{N}_{2}$ a $\mathrm{NH}_{3}$ é realizada por microrganismos que contém a enzima nitrogenase e são conhecidos como fixadores de $\mathrm{N}_{2}$ ou diazotróficos (BERGAMASCHI, 2006). Várias bactérias diazotróficas foram isoladas da cultura de milho, destacando-se as espécies Azospirillum lipoferum, Azospirillum brasilense e Herbaspirillum seropedicae, sendo as espécies mais estudadas as do gênero Azospirillum (REIS et al., 2000).

As bactérias do gênero Azospirillum são endofíticas facultativas e colonizam tanto o interior quanto a superfície das raízes, sendo que além do milho são plantas hospedeiras desta bactéria o trigo, arroz, sorgo e aveia (BASHAN apud BERGAMASCHI, 2006). Além disso, vários autores têm verificado que o efeito estimulatório exercido por este gênero de bactérias tem sido atribuído a diversos mecanismos, sendo que 
além da FBN há que se considerar a produção de hormônios vegetais (BERGAMASCHI, 2006; MENDONÇA; URQUIAGA; REIS, 2006).

Nesse sentido, vários trabalhos com Azopirillum spp. têm demonstrado aumento no rendimento de massa seca e o acúmulo de nutrientes por plantas inoculadas (REIS JÚNIOR et al., 2008) e na produtividade de grãos de milho (CAVALLET et al., 2000; DOBBELAERE et al., 2002, HUNGRIA et al., 2010).

Entretanto, resultados da interação bactérias diazotróficas e milho em termos de potencial agronômico, fixação de nitrogênio ou promoção do crescimento, depende de muitos fatores bióticos e ambientais, tais como genótipo da planta, comunidade microbiológica do solo e disponibilidade de nitrogênio (ROESCH et al., 2006).

Como não há relatos na literatura sobre o uso da inoculação de bactérias diazotróficas em sistemas de integração lavoura-pecuária, o objetivo do presente trabalho foi avaliar a associação do efeito residual da adubação nitrogenada na pastagem de inverno e a inoculação de Azospirillum brasilense na cultura do milho.

\section{Material e Métodos}

Dois experimentos foram conduzidos, em área de integração lavoura-pecuária, durante a safra agrícola 2008/2009 na Fazenda Galo Vermelho, em Guarapuava (PR). A região apresenta altitude de aproximadamente $1100 \mathrm{~m}$, e seu clima, segundo a classificação de Köppen, é do tipo $\mathrm{Cfb}$, sendo subtropical mesotérmico úmido, com verões amenos e sem estação seca definida (IAPAR, 2011). O solo da área experimental é classificado como Latossolo Bruno Distroférrico típico (EMBRAPA, 2006) apresentando, na profundidade de 0 a 20 $\mathrm{cm}$, as seguintes características químicas: $\mathrm{pH}$ em $\mathrm{CaCl}_{2}$ : 5,2; matéria orgânica: $35,6 \mathrm{~g} \mathrm{dm}^{-3}$; fósforo (P): $1,5 \mathrm{mg} \mathrm{dm}^{-3}$; potássio $\left(\mathrm{K}^{+}\right): 0,38 \mathrm{cmol}_{\mathrm{c}} \mathrm{dm}^{-3}$; cálcio $\left(\mathrm{Ca}^{2+}\right): 4,4 \mathrm{cmol}_{\mathrm{c}} \mathrm{dm}^{-3}$; magnésio $\left(\mathrm{Mg}^{2+}\right): 2,1$ $\mathrm{cmol}_{\mathrm{c}} \mathrm{dm}^{-3}$; alumínio $\left(\mathrm{Al}^{3+}\right): 0,0 \mathrm{cmol}_{\mathrm{c}} \mathrm{dm}^{-3} ; \mathrm{H}+\mathrm{Al}$ : $4,76 \mathrm{cmol}_{\mathrm{c}} \mathrm{dm}^{-3}$; CTC: $11,36 \mathrm{cmol}_{\mathrm{c}} \mathrm{dm}^{-3}$.

A cultura do milho foi implantada em sucessão a pastagem de aveia preta (Avena strigosa L.) e azevém (Lollium multiflorum Lam.) ocupada por bovinos de corte da raça Abeerden e Charolês em sistema de pastejo contínuo. A semeadura da pastagem foi realizada no dia 15/04/08 com 60 $\mathrm{kg} \mathrm{ha}^{-1}$ de aveia preta e $30 \mathrm{~kg} \mathrm{ha}^{-1}$ de azevém com espaçamento entre linhas de $17 \mathrm{~cm}$. Foi utilizado delineamento experimental de blocos casualizados, com cinco tratamentos e três repetições. Os tratamentos consistiram na aplicação de $\mathrm{N}$ em cobertura na pastagem no dia $15 / 06 / 08$, tendo como fonte a uréia $(45 \%$ de $\mathrm{N})$, nas doses de zero, $75,150,225$ e $300 \mathrm{~kg} \mathrm{ha}^{-1}$. O período de pastejo correspondeu a 90 dias (05/06/08 a 05/09/08). Verificou-se que o resíduo do pastejo apresentouse com altura inferior a $3 \mathrm{~cm}$, assim, após a retirada dos animais a área foi dessecada com glifosato a 720 g i.a. ha ${ }^{-1}$.

$\mathrm{Na}$ cultura do milho foi utilizado delineamento experimental de blocos casualizados com parcelas subdivididas em três repetições. A parcela principal consistiu nos tratamentos com aplicação de $\mathrm{N}$ no inverno e as subparcelas aos tratamentos de verão no milho: $\mathrm{T} 1$ = controle; $\mathrm{T} 2$ = inoculação de Azospirillum brasilense; $\mathrm{T} 3=75 \mathrm{~kg} \mathrm{ha}^{-1} \mathrm{de} \mathrm{N}$; $\mathrm{T} 4=150 \mathrm{~kg} \mathrm{ha}^{-1}$ de N. A unidade experimental constitui-se de quatro linhas de semeadura com 5 $\mathrm{m}$ de comprimento, sendo a área útil para avaliação de $8 \mathrm{~m}^{2}$ (2 linhas centrais x $\left.0,8 \mathrm{~m} \times 5 \mathrm{~m}\right)$.

No tratamento correspondente, para inoculação das sementes de milho, utilizou-se inoculante líquido, fornecido pela empresa Nitral Urbana à base da bactéria Azospirillum brasilense, cepa BR 11005 (Sp 245), numa concentração de 1 x $10^{8}$ unidades formadoras de colônia por grama de produto, veiculada através de turfa $\left(30 \mathrm{~g} \mathrm{~kg}^{-1}\right.$ de sementes de milho).

A semeadura do experimento 1 foi realizada no 
dia 15/09/08 e do experimento 2 no dia 15/10/08, em sistema de semeadura direta, com $0,8 \mathrm{~m}$ de espaçamento entre linhas. Aplicou-se $108 \mathrm{~kg} \mathrm{ha}^{-1}$ de $\mathrm{K}_{2} \mathrm{O}$ e $105 \mathrm{~kg} \mathrm{ha}^{-1}$ de $\mathrm{P}_{2} \mathrm{O}_{5}$ utilizando com fonte o cloreto de potássio $\left(60 \% \mathrm{~K}_{2} \mathrm{O}\right)$ e superfosfato triplo $\left(45 \% \mathrm{P}_{2} \mathrm{O}_{5}\right)$, ambos em cobertura. $\mathrm{O} \mathrm{N}$, de acordo com dose, foi aplicado $1 / 3$ da dose na linha de semeadura e 2/3 em cobertura, sendo metade no estádio fenológico V2 (duas folhas expandidas) e o restante em estádio fenológico V5 (cinco folhas expandidas), utilizando-se a uréia $(45 \%$ de $\mathrm{N})$. Realizou-se, em estádio V2 desbaste das plantas, para ajuste da densidade populacional.

As variáveis avaliadas foram população final de plantas, índice de espigamento, produtividade, número de fileiras de grãos por espiga, número de grãos por fileira, massa de mil grãos e teor de grãos ardidos.

O ajuste da população foi realizado por meio de desbaste das plantas em estádio V2 de desenvolvimento das plantas, contudo, fez-se a contagem antes da colheita do número de plantas na área útil da parcela de forma a verificar se não houve morte de plantas posteriormente ao desbaste. O índice de espigamento foi obtido pela relação entre o número de espigas e de plantas na área útil da parcela. A colheita do milho foi efetuada no estádio de maturação fisiológica das plantas e depois da correção da umidade para $14 \%$, o valor obtido foi convertido para $\mathrm{kg} \mathrm{ha}^{-1}$. Para avaliação do número de fileiras e grãos por fileira foram utilizadas dez espigas, colhidas em sequência, da segunda linha central de cada parcela, que após analisadas foram incorporadas ao peso da parcela. A massa de mil grãos foi estimada a partir da pesagem de 300 grãos de cada parcela. Além das variáveis quantitativas, fez-se a avaliação qualitativa por meio do teor de grãos ardidos, o qual foi obtido pela avaliação de uma amostra de $250 \mathrm{~g}$ e posteriormente obteve-se a porcentagem relativa dos grãos ardidos que compunham esta amostra. Foi considerado como ardido, aquele grão que perdeu a coloração característica por ação do calor, umidade ou fermentação por fungos em mais de $1 / 4$ do seu tamanho.

Os dados obtidos foram submetidos à análise de variância e as médias comparadas pelo Teste de Tukey a $5 \%$ de probabilidade para o fator qualitativo (época de semeadura), por meio do programa estatístico Sisvar, e por regressão para o fator quantitativo (doses de N), buscando-se o modelo que melhor expressasse a relação entre a variável independente (doses de $\mathrm{N}$ no inverno) com as variáveis dependentes através da planilha eletrônica Microsoft Excel. Foram testados modelos linear e quadrático e a escolha foi baseada na significância (menor que 5\%).

\section{Resultados e Discussão}

\section{Experimento 1}

Apartir do resumo da análise de variância (Tabela 1) pode-se constatar que a população de plantas de milho foi afetada pelos tratamentos aplicados na cultura da mesma forma como observado para o índice de espigamento, produtividade, massa de mil grãos, número de fileiras de grãos por espiga e grãos por fileira. As doses de $\mathrm{N}$ aplicadas na pastagem afetaram a produtividade de milho, massa de mil grãos e número de grãos por fileira, enquanto que, a interação entre os tratamentos na pastagem e na cultura do milho apresentaram efeito apenas sobre a produtividade e número de grãos por fileira.

A população de plantas de milho foi inferior ao controle quando foram aplicados $150 \mathrm{~kg} \mathrm{ha}^{-1}$ de N e quando se fez a inoculação com $A$. brasilense (Tabela 2), sendo este resultado, portanto, contrário ao obtido por Campos, Theisen e Gnatta (2000) que não verificaram diferenças significativas para número de plantas em trabalho onde foi testado o inoculante comercial Graminate ${ }^{\circledR}$ individualmente e em associação com adubação nitrogenada na semeadura e em cobertura na cultura do milho. 


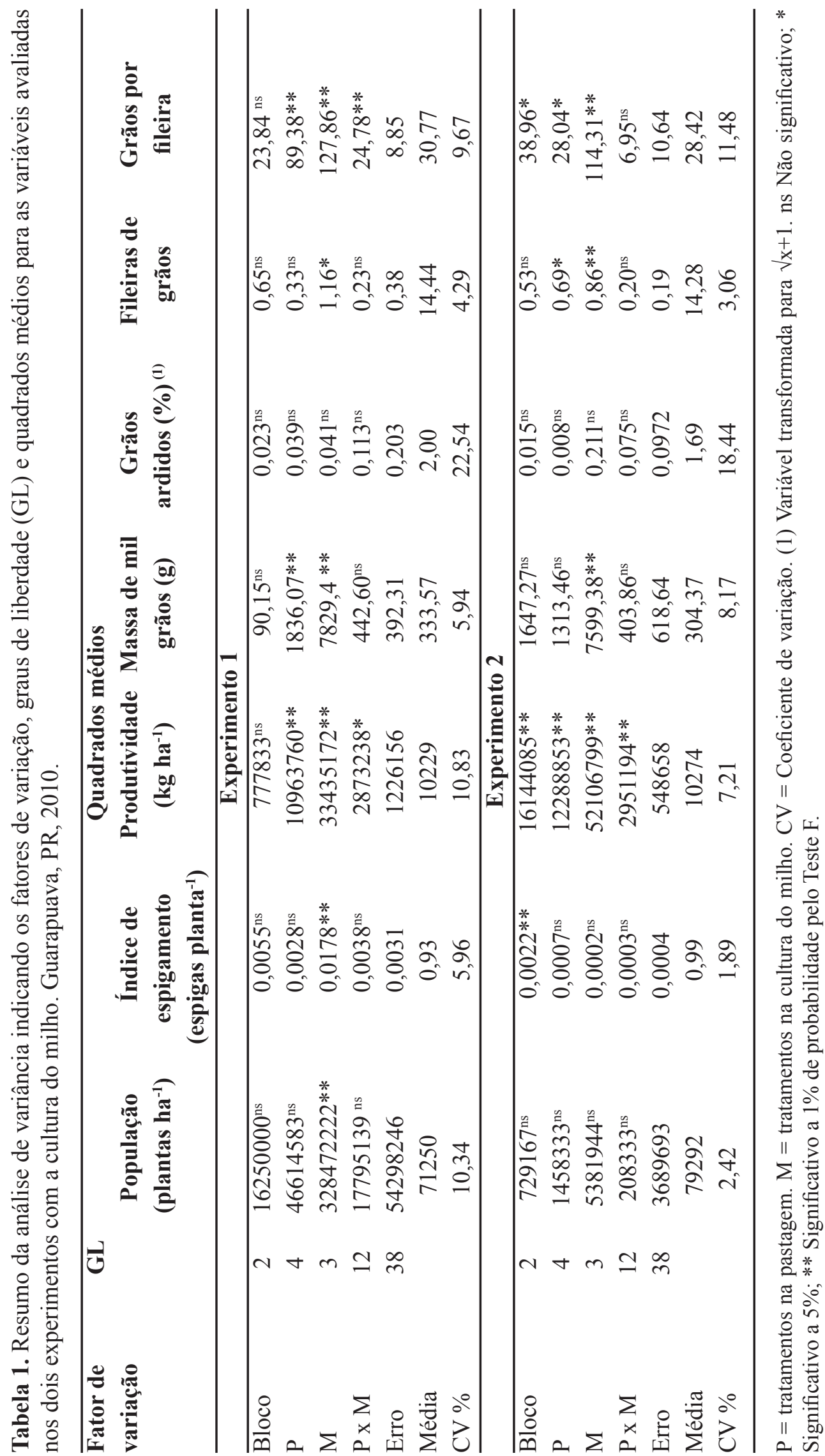


Tabela 2. População de plantas, índice de espigamento, massa de mil grãos, incidência de grãos ardidos, número de fileiras de grãos por espiga e número de grãos por fileira de milho em dois experimentos com aplicação de diferentes doses de nitrogênio e inoculação de Azospirillum brasilense. Guarapuava, PR, 2011.

\begin{tabular}{lcccccc}
\hline $\begin{array}{l}\text { Tratamentos } \\
\text { na cultura }\end{array}$ & $\begin{array}{c}\text { População } \\
\text { (plantas ha }^{-1} \text { ) }\end{array}$ & $\begin{array}{c}\text { Índice de } \\
\text { espigamento }\end{array}$ & $\begin{array}{c}\text { Massa de mil } \\
\text { grãos (g) }\end{array}$ & $\begin{array}{c}\text { Grãos } \\
\text { ardidos (\%) }\end{array}$ & $\begin{array}{c}\text { Fileiras de } \\
\text { grãos por espiga }\end{array}$ & $\begin{array}{c}\text { Grãos } \\
\text { por fileira }\end{array}$ \\
\hline $75 \mathrm{~kg} \mathrm{ha}^{-1} \mathrm{~N}$ & $70667 \mathrm{ab}$ & $0,960 \mathrm{a}$ & $343,08 \mathrm{ab}$ & $2,92 \mathrm{a}$ & $14,73 \mathrm{a}$ & $33,39 \mathrm{a}$ \\
$150 \mathrm{~kg} \mathrm{ha}^{-1} \mathrm{~N}$ & $66833 \mathrm{~b}$ & $0,954 \mathrm{a}$ & $357,84 \mathrm{a}$ & $3,51 \mathrm{a}$ & $14,59 \mathrm{ab}$ & $32,82 \mathrm{a}$ \\
A. brasilense & $69667 \mathrm{~b}$ & $0,936 \mathrm{ab}$ & $329,25 \mathrm{~b}$ & $3,23 \mathrm{a}$ & $14,36 \mathrm{ab}$ & $29,80 \mathrm{~b}$ \\
Controle & $77833 \mathrm{a}$ & $0,884 \mathrm{~b}$ & $304,11 \mathrm{c}$ & $2,98 \mathrm{a}$ & $14,09 \mathrm{~b}$ & $27,09 \mathrm{~b}$ \\
\hline Média & 71250 & 0,93 & 333,57 & 3,16 & 14,44 & 30,77 \\
$\mathrm{CV} \%$ & 10,34 & 5,96 & 5,94 & 22,54 & 4,29 & 9,67 \\
\hline $75 \mathrm{~kg} \mathrm{ha}^{-1} \mathrm{~N}$ & $79833 \mathrm{a}$ & $0,994 \mathrm{a}$ & $308,65 \mathrm{~b}$ & $1,69 \mathrm{a}$ & $14,31 \mathrm{ab}$ & $29,59 \mathrm{ab}$ \\
$150 \mathrm{~kg} \mathrm{ha}^{-1} \mathrm{~N}$ & $79167 \mathrm{a}$ & $0,987 \mathrm{a}$ & $334,49 \mathrm{a}$ & $1,53 \mathrm{a}$ & $14,61 \mathrm{a}$ & $31,75 \mathrm{a}$ \\
A. brasilense & $78500 \mathrm{a}$ & $0,987 \mathrm{a}$ & $285,97 \mathrm{~b}$ & $2,11 \mathrm{a}$ & $14,12 \mathrm{~b}$ & $25,80 \mathrm{c}$ \\
Controle $^{7}$ & $79667 \mathrm{a}$ & $0,992 \mathrm{a}$ & $288,38 \mathrm{~b}$ & $2,46 \mathrm{a}$ & $14,09 \mathrm{~b}$ & $26,53 \mathrm{bc}$ \\
\hline Média & 79292 & 0,99 & 304,37 & 1,69 & 14,28 & 28,42 \\
CV \% & 2,42 & 1,89 & 8,17 & 18,44 & 3,06 & 11,48 \\
\hline
\end{tabular}

Médias seguidas pela mesma letra não diferem entre si pelo Teste de Tukey a $5 \%$ de probabilidade.

A adubação nitrogenada na cultura do milho, independentemente da dose, proporcionou maior índice de espigamento do que o controle. Para o número de grãos por espiga as doses de $\mathrm{N}$ também não apresentaram diferença significativa entre si, contudo foram superiores ao controle e a inoculação de $A$. brasilense, ao passo que o número de fileiras de grãos por espiga somente foi maior do que o controle quando foram aplicados $75 \mathrm{~kg} \mathrm{ha}^{-1}$ de $\mathrm{N}$. Quando foi efetuada a inoculação de $A$. brasilense a massa de mil grãos foi inferior à adubação nitrogenada, contudo superior ao controle. $\mathrm{O}$ efeito pela adubação nitrogenada sobre os componentes da produção de milho já foram descritos por outros autores (AMARAL FILHO et al., 2005; GOMES et al., 2007; SANGOI; ERNANI; SILVA, 2007; GAVA et al., 2010; MELO; CORÁ; MILTON, 2011), tendo em vista que é um dos nutrientes requeridos em maior quantidade pelas plantas, sendo componente de moléculas de proteínas, enzimas, coenzimas, ácidos nucléicos e citocromos.
A produtividade de milho não apresentou resposta significativa das doses de $\mathrm{N}$ aplicadas na pastagem quando foram utilizados $150 \mathrm{~kg} \mathrm{ha}^{-1}$ de $\mathrm{N}$ na cultura no verão, o que possivelmente se deve ao efeito residual do $\mathrm{N}$ aplicado no inverno sobre a cultura subsequente, uma vez que para os demais tratamentos obteve-se resposta quadrática com nível de significância de 1\% (Figura 1). Tais resultados corroboram com os obtidos por Assmann et al. (2003), onde os autores verificaram que com aplicação de $300 \mathrm{~kg} \mathrm{ha}^{-1}$ de $\mathrm{N}$ no inverno na pastagem não se teve resposta da adubação nitrogenada na cultura do milho subsequente, decorrente do fato de que grande parte do $\mathrm{N}$ aplicado no inverno estava disponível para o cultivo posterior e, conseqüentemente, não necessitou de adubações nitrogenadas.

A produtividade de milho manteve-se superior com a inoculação de $A$. brasilense quando comparada ao controle mesmo com o aumento da quantidade de $\mathrm{N}$ aplicada no inverno (Figura 1). Hungria 
et al. (2010) também obtiveram incrementos na produtividade de milho, e dependendo da estirpe de A. brasilense avaliada, o aumento na produtividade foi da ordem de 24 a 30\%, correspondendo a 662 a $823 \mathrm{~kg} \mathrm{ha}^{-1}$. Cavallet et al. (2000) também obtiveram resultados positivos, constatando aumento de $17 \%$ na produtividade de grãos de milho, de 5211 para $6067 \mathrm{~kg} \mathrm{ha}^{-1}$, e de $6 \%$ na média do comprimento das espigas, quando inocularam as sementes de milho com Azospirillum. Entretanto, é necessário considerar que as condições de cultivo podem afetar o desempenho esperado com o uso de bactérias diazotróficas, uma vez que em trabalho de Campos, Theisen e Gnatta (2000) com a utilização do inoculante Graminante ${ }^{\circledR}$ não houve resposta para rendimento de grãos, o que possivelmente deu-se em função da especificidade da bactéria ao genótipo avaliado.

Figura 1. Produtividade e número de grãos por fileira de milho com aplicação de $75 \mathrm{~kg} \mathrm{ha}^{-1}$ de N, $150 \mathrm{~kg}$ ha $^{-1}$ de N, inoculação com Azospirillum brasilense e controle em função das doses crescentes de nitrogênio aplicadas na pastagem no experimento 1. Guarapuava, PR, 2011.

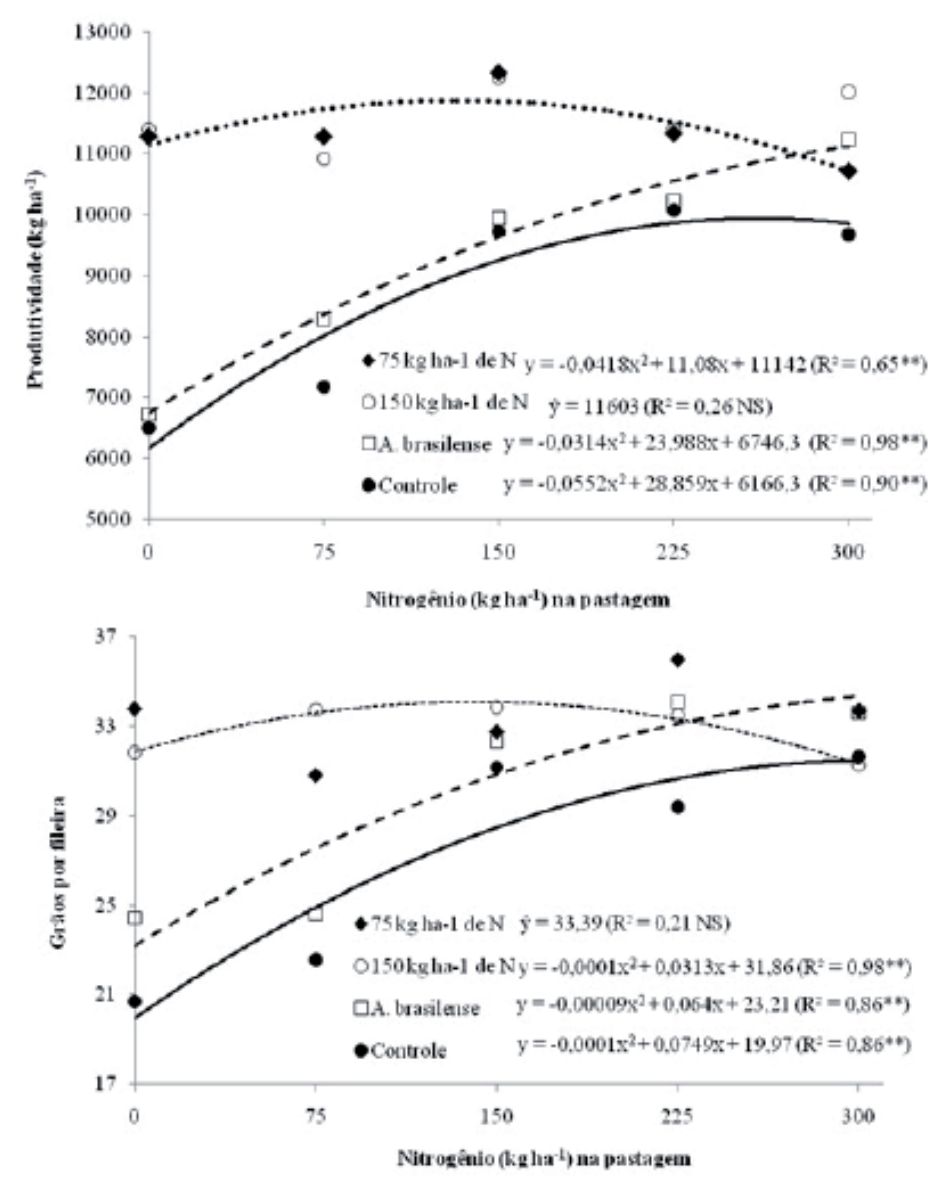

Para o controle, a aplicação de $261 \mathrm{~kg} \mathrm{ha}^{-1}$ proporcionaria a máxima produtividade de milho com $9938 \mathrm{~kg} \mathrm{ha}^{-1}$. Esta mesma produtividade, para o tratamento com a inoculação de $A$. brasilense seria obtida com a aplicação de $172 \mathrm{~kg} \mathrm{ha}^{-1}$, o que representa uma economia de $89 \mathrm{~kg} \mathrm{ha}^{-1}$ de
N. De acordo com Dobbelaere, Vanderleyden e Okon (2003) respostas positivas são obtidas pela inoculação com $A$. brasilense inclusive quando cultivadas com altos níveis de nitrogênio, o que indica que as respostas da planta não ocorrem apenas em razão do $\mathrm{N}_{2}$ fixado, mas, também, 
da produção de outras substâncias. Tal fato, possivelmente pode ter afetado o desenvolvimento radicular do milho melhorando a eficiência de aproveitamento do $\mathrm{N}$ residual, absorção de água e de outros nutrientes. Bashan, Holguin e De-Bashan (2004) mencionaram que ocorre excreção de hormônios vegetais, principalmente o ácido indolacético (AIA) por bactérias do gênero Azospirillum que desempenham papel essencial na promoção do crescimento de plantas, e que podem melhorar, segundo Hungria et al. (2010), a absorção de vários macro e micronutrientes aumentando a eficiência do uso do nutriente disponível.

Para o número de grãos por fileira houve resposta quadrática no controle, com a inoculação de $A$. brasilense e com a aplicação de $150 \mathrm{~kg} \mathrm{ha}^{-1}$ de N no milho com o aumento da dose aplicada na pastagem (Figura 2). Com base na Figura 3, verifica-se que a população de plantas apresentou decréscimo com doses de nitrogênio na pastagem acima de $86 \mathrm{~kg} \mathrm{ha}^{-1}$ de N. Contudo, constatou-se acréscimo no índice de espigamento que também apresentou resposta quadrática pelas doses de nitrogênio na pastagem, assim como o número fileiras de grãos por espiga. A massa de mil grãos apresentou resposta quadrática com o aumento da dose de nitrogênio na pastagem durante o inverno (Figura 2). Gomes et al. (2007), ao contrário deste trabalho não verificaram efeito sobre a massa de mil grãos com o aumento da dose de $\mathrm{N}$ aplicada na cultura do milho.

Figura 2. População de plantas (A), índice de espigamento (B), massa de mil grãos (C) e número de fileiras de grãos por espiga (D) de milho com o aumento da dose de nitrogênio aplicada na pastagem durante o inverno no experimento 1. Guarapuava, PR, 2011.
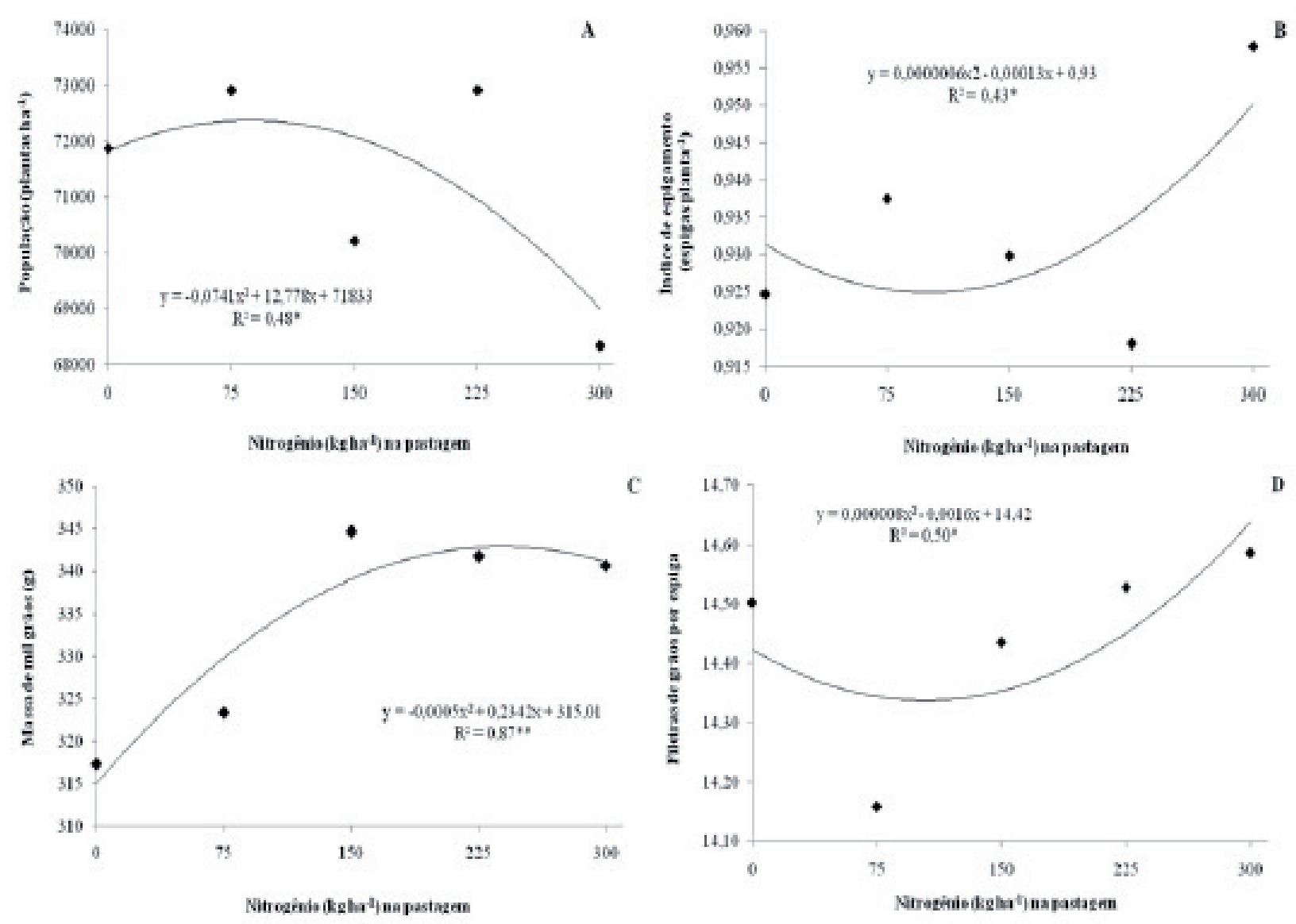


\section{Experimento 2}

A produtividade de milho apresentou efeito das doses crescentes de $\mathrm{N}$ aplicadas na pastagem, dos tratamentos de base da cultura do milho no verão e de sua interação (Tabela 1). Os tratamentos na pastagem e no milho afetaram o número de fileiras de grãos por espiga e número de grãos por fileira, enquanto que a massa de mil grãos somente apresentou efeito dos tratamentos aplicados na cultura do milho.

A produtividade e massa de mil grãos de milho foram superiores com a aplicação de $150 \mathrm{~kg} \mathrm{ha}^{-1}$ de $\mathrm{N}$ quando comparado aos demais tratamentos (Tabela 2). A inoculação de $A$. brasilense não apresentou diferença significativa do controle para nenhuma das variáveis avaliadas.

Com relação ao efeito sobre a produtividade (Figura 3), ao contrário do experimento 1 que se teve resposta quadrática, no experimento 2 a resposta foi linear para o controle e para o tratamento com inoculação de Azospirillum brasilense, não se tendo efeito significativo na dose de $75 \mathrm{~kg} \mathrm{ha}^{-1}$ de
$\mathrm{N}$ e com resposta quadrática na dose de $150 \mathrm{~kg} \mathrm{ha}^{-1}$ de N. Verifica-se também que a inoculação com $A$. brasilense foi superior ao controle até a dose de $225 \mathrm{~kg} \mathrm{ha}^{-1}$, sendo que a partir desta dose o efeito é semelhante ao controle o que possivelmente é decorrente do efeito residual da adubação na pastagem durante o inverno. Esta diferença observada em relação ao experimento 1 pode ser decorrente da diferença da época da semeadura, de forma que se tivesse maior precipitação acumulada (Figura 4) desde a aplicação do nitrogênio na pastagem até a semeadura do milho que no experimento 2 correspondeu a $617 \mathrm{~mm}$ enquanto que no experimento 1 foi de $372 \mathrm{~mm}$, o que pode ter afetado a dinâmica no nitrogênio no solo. Em trabalho desenvolvido por Balbinot Junior et al. (2008) não se verificou efeito residual do $\mathrm{N}$ aplicado no inverno por consequência das elevadas precipitações ocorridas em período anterior à implantação da cultura do milho o que, segundo os autores, pode ter acarretado perdas do $\mathrm{N}$ por lixiviação.

Figura 3. Produtividade de milho com aplicação de $75 \mathrm{~kg} \mathrm{ha}^{-1}$ de $\mathrm{N}, 150 \mathrm{~kg} \mathrm{ha}^{-1}$ de $\mathrm{N}$, inoculação com Azospirillum brasilense e controle em função das doses crescentes de nitrogênio aplicadas na pastagem no experimento 2. Guarapuava, PR, 2011.

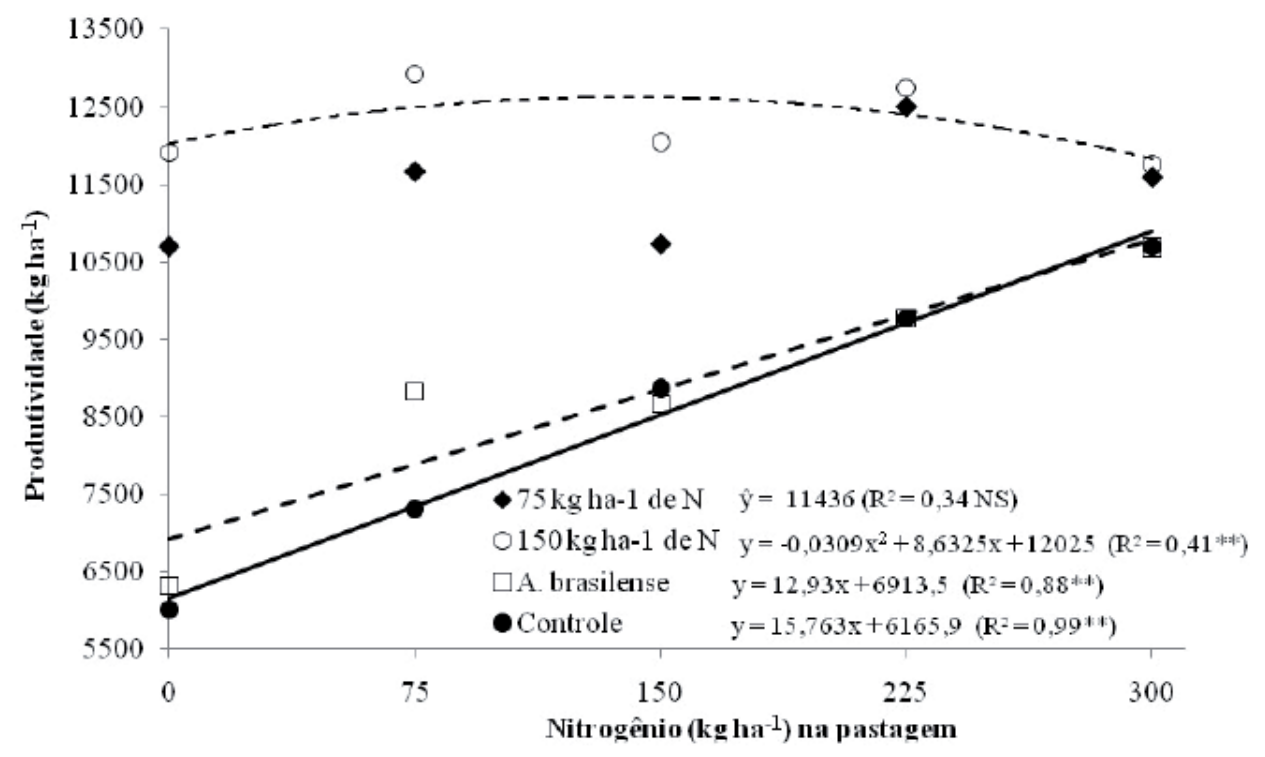


Figura 4. Temperatura $\left({ }^{\circ} \mathrm{C}\right)$ máxima, média e mínima e precipitação acumulada por decêndio durante o período de condução do experimento (mês de abril de 2008 - mês de abril de 2009). Guarapuava, PR, 2011.

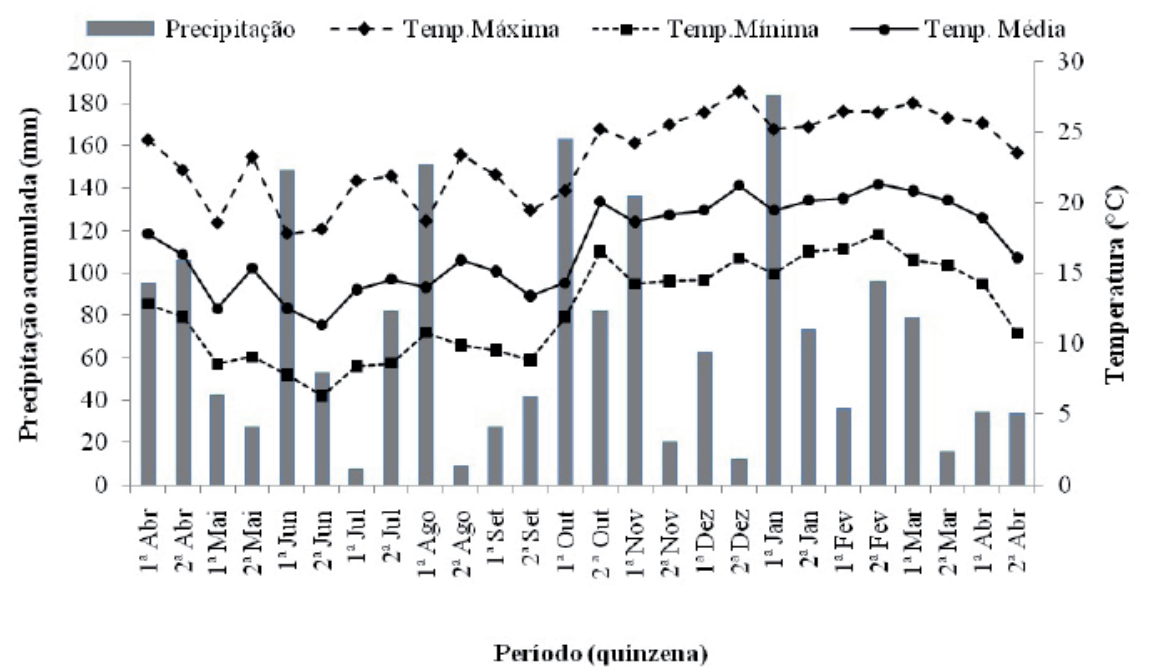

Algumas pesquisas em trigo têm sugerido que a inoculação com bactérias diazotróficas não substitui o adubo nitrogenado, porém, pode promover melhor absorção e utilização do $\mathrm{N}$ disponível (SAUBIDET; FATTA; BARNEIX, 2002). Quadros (2009) observou que a inoculação a campo apresentou indícios de que juntamente com a adição de dose de $50 \mathrm{~kg} \mathrm{ha}^{-1}$ na base, apresenta desempenho equivalente à aplicação de $130 \mathrm{~kg} \mathrm{ha}^{-1}$ de $\mathrm{N}$ quanto ao rendimento de grãos para dois híbridos de milho. Didonet, Rodrigues e Kenner (1996) observaram que a produção de grãos de trigo inoculado com $A$. brasilense, e complementado com $15 \mathrm{~kg} \mathrm{ha}^{-1}$ de $\mathrm{N}$ não diferiu estatisticamente da obtida no tratamento controle com $45 \mathrm{~kg} \mathrm{ha}^{-1}$ de $\mathrm{N}$.

Roesch et al. (2006) verificaram que a colonização de plantas de milho por bactérias diazotróficas foi inibida por altas doses de nitrogênio durante os primeiros estádios de crescimento. O efeito observado não é um efeito negativo direto sobre a bactéria, mas reside no fato de que o $\mathrm{N}$ pode alterar o estado fisiológico da planta e por conseqüência a sua associação as bactérias diazotróficas (REIS JÚNIOR et al., 2000).

De forma semelhante ao que ocorreu no experimento 1, no experimento 2 a massa de mil grãos e o número de grãos por fileira de milho apresentou resposta quadrática, enquanto que o número de fileiras de grãos por espiga apresentou resposta linear crescente com o aumento da dose de $\mathrm{N}$ na pastagem (Figura 5).

Como relatado por Hungria et al. (2010) apesar de muitos experimentos com fertilização nitrogenada conduzirem para produtividades superiores quando comparado ao uso da inoculação de bactérias diazotróficas como o $A$. brasilense, isto não reduz o potencial de seu uso. Nesse sentido, a inoculação de $A$. brasilense e a integração lavoura-pecuária podem contribuir para economia de fertilizante nitrogenado, assim como melhorar a eficiência de uso dos recursos disponíveis com a intensificação do uso da terra, porém desenvolvendo-se um sistema de produção baseado em um conceito de agricultura sustentável. 
Figura 5. Massa de mil grãos, número de fileiras de grãos número de grãos por espiga de milho com o aumento da dose de nitrogênio aplicada na pastagem durante o inverno no experimento 2. Guarapuava, PR, 2011.

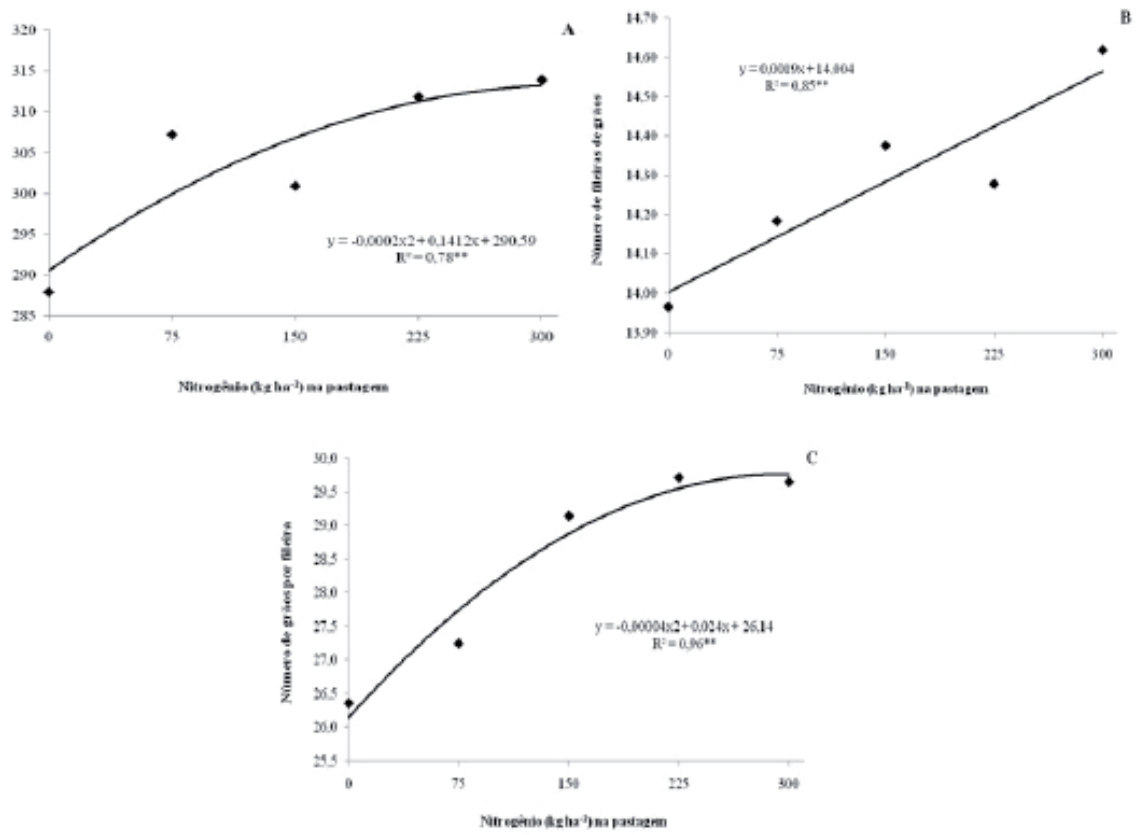

\section{Referências}

AMARAL FILHO, J. P. R.; FORNASIERI FILHO, D.; FARINELLI, R.; BARBOSA, J. C. Espaçamento, densidade populacional e adubação nitrogenada na cultura do milho. Revista Brasileira de Ciência do Solo, Viçosa, MG, v. 29, n. 3, p. 467-473, 2005.

ASSMANN, T. S.; ROZELLI JUNIOR; P.; MORAES, A.; ASSMANN, A. L.; KOEHLER, H. S.; SANDINI, I. Rendimento de milho em área de integração lavourapecuária sob o sistema de plantio direto, em presença e ausência de trevo branco, pastejo e nitrogênio. Revista Brasileira de Ciência do Solo, Viçosa, MG, v. 27, n. 4, p. 675-683, 2003.

BALBINOT JUNIOR, A. A.; MORAES, A.; PELISSARI, A.; DIECKOW, J. VEIGA, M. Formas de uso do solo no inverno e sua relação com a infestação de plantas daninhas em milho (Zea mays) cultivado em sucessão. Planta Daninha, Viçosa, MG, v. 26, n. 3, p. 569-576, 2008.

BASHAN, Y.; HOLGUIN, G.; DE-BASHAN, L. E. Azospirillum-plant relationships: physiological, molecular, agricultural and envioronmental advances (1997-2003). Canadian Journal of Microbiology, Ottawa, v. 50, n. 8, p. 521-577, 2004.

BERGAMASCHI, C. Ocorrência de bactérias diazotróficas associadas às raízes e colmos de cultivares de sorgo. 2006. Dissertação (Mestrado em Microbiologia Agrícola) - Universidade Federal do Rio Grande do Sul, Porto Alegre.

CAMPOS, B. H. C.; THEISEN, S.; GNATTA, V. Avaliação de inoculante Graminante na cultura do milho. Ciência Rural, Santa Maria, v. 30, n. 4, p. 713-715, 2000.

CANTARELLA, H. Nitrogênio. In: NOVAIS, R. F.; ALVAREZ, V. H.; BARROS, N. F; FONTES, R. L.; CANTARUTTI, R. B.; NEVES, J. C. L. (Ed.). Fertilidade do solo. Viçosa, MG: Sociedade Brasileira de Ciência do Solo, 2007. p. 375-470.

CAVALLET, L. E.; PESSOA, A. C. dos S.; HELMICH, J. J.; HELMICH, P. R.; OST, C. F. Produtividade do milho em resposta à aplicação de nitrogênio e inoculação das sementes com Azospirillum spp. Revista Brasileira de Engenharia Agrícola e Ambiental, Campina Grande, v. 4, p. 129-132, 2000.

DIDONET, A. D.; RODRIGUES, O.; KENNER, M. H. Acúmulo de nitrogênio e de massa seca em plantas de trigo inoculadas com Azospirillum brasiliense. Pesquisa Agropecuária Brasileira, v. 31, n. 9, p. 645-651, 1996.

DOBBELAERE, S.; CROONENBORGHS, A.; THYS, A.; PTACEK, D.; OKON, Y.; VANDERLEYDEN, J. Effect of inoculation with wild type Azospirillum brasilense and $A$. irakense strains on development and nitrogen uptake of spring wheat and grain maize. Biology 
and Fertility of Soils, Berlin, v. 36, n. 4, p. 284-297, 2002.

DOBBELAERE, S.; VANDERLEYDEN, J.; OKON, Y. Plant growth-promoting effects of diazotrophs in the rhizosphere. Critical Reviews in Plant Sciences, Amsterdan, v. 22, n. 2, p. 107-149, 2003.

EMPRESA BRASILEIRA DE PESQUISA AGROPECUÁRIA - EMBRAPA. Sistema brasileiro de classificação de solos. 2. ed. Rio de Janeiro: EMBRAPA Solos, 2006.

FERNANDES, F. C. S.; LIBARDI, P. L.; TRIVELIN, P. C. O. Parcelamento da adubação nitrogenada na cultura do milho e utilização do $\mathrm{N}$ residual pela sucessão aveia preta - milho. Ciência Rural, Santa Maria, v. 38, n. 4, p. 1138-1141, 2008.

GAVA, G. J. de C.; OLIVEIRA, M. W.; SILVA, M. de A.; JERÔNIMO, E. M.; CRUZ, J. C. S.; TRIVELIN, P. C. O. Produção de fitomassa e acúmulo de nitrogênio em milho cultivado com diferentes doses de $15 \mathrm{~N}$-uréia. Semina: Ciências Agrárias, Londrina, v. 31, n. 4, p. 851$862,2010$.

GOMES, R. F.; SILVA, A. G. da; ASSIS, R. L. de; PIRES, F. R. Efeito de doses e da época de aplicação de nitrogênio nos caracteres agronômicos da cultura do milho sob plantio direto. Revista Brasileira de Ciência do Solo, Viçosa, v. 31, n. 5, p. 931-938, 2007.

HERINGER, I.; MOOJEN, E. L. Potencial produtivo, alterações da estrutura e qualidade da pastagem de milheto submetida a diferentes níveis de nitrogênio. Revista Brasileira de Zootecnia, Viçosa, MG, v. 31, n. 2, p. 875-882, 2002. Suplemento.

HUNGRIA, M.; CAMPO, R. J.; SOUZA, E. M. S.; PEDROSA, F. O. Inoculation with selected strains of Azospirillum brasilense and A. lipoferum improves yields of maize and wheat in Brazil. Plant and Soil, Netherlands, v. 331, n. 1/2, p. 413-425, 2010.

INSTITUTO AGRONÔMICO DO PARANÁ IAPAR. Cartas climáticas do Paraná. Disponível em: $<$ http://www.iapar.br/modules/conteudo/conteudo. php? conteudo=863>. Acesso em: 10 jun. 2011.

MELO, F. de B.; CORÁ, J. R.; MILTON, J. Fertilização nitrogenada, densidade de plantas e rendimento de milho cultivado no sistema plantio direto. Revista Ciência Agronômica, Fortaleza, v. 42, n. 1, p. 27-31, 2011.

MENDONÇA, M. M.; URQUIAGA, S. S.; REIS, V. M. Variabilidade genotípica de milho para acumulação de nitrogênio e contribuição da fixação biológica de nitrogênio. Pesquisa Agropecuária Brasileira, Brasília, v. 41, n. 11, p. 1681-1685, 2006.

NICOLOSO, R. S.; LANZANOVA, M. E.; LOVATO, T.
Manejo das pastagens de inverno e potencial produtivo de sistemas de integração lavoura-pecuária no estado do Rio Grande do Sul. Ciência Rural, Santa Maria, v. 36, n. 6, p. 1799-1805, 2006.

PARIS, W.; CECATO, U.; BRANCO, A. F.; BARBERO, L. M.; GALBEIRO, S. Produção de novilhas de corte em pastagem de Coastcross-1 consorciada com Arachis pintoi com e sem adubação nitrogenada. Revista Brasileira de Zootecnia, Viçosa, MG, v. 38, n. 1, p. 122129, 2009.

QUADROS, P. D. Inoculação de Azospirillum spp. em sementes de genótipos de milho cultivados no Rio Grande do Sul. 2009. Dissertação (Mestrado em Ciência do Solo) - Universidade Federal do Rio Grande do Sul, Porto Alegre.

REIS JUNIOR, F. B. dos; MACHADO, C. T. de T.; MACHADO, A. T.; SODEK, L. Inoculação de Azospirillum amazonense em dois genótipos de milho sob diferentes regimes de nitrogênio. Revista Brasileira de Ciência do Solo, Viçosa, MG, v. 32, n. 3, p. 11391146, 2008.

REIS JÚNIOR, F. B.; DÖBEREINER, J.; BALDANI, V. L. D.; REIS, V. M.; MACHADO, A. T. Seleção de genótipos de milho e arroz mais eficientes quanto ao ganho de $N$ através de fixação biológica de $N_{2}$, Seropédica: EMBRAPA Agrobiologia, nov. 1998. 23 p. (Documento, n. 73).

REIS, V. M.; BALDANI, V. L. D.; BALDANI, J. I.; DÖBEREINER, J. Biological nitrogen fixation in gramineae and palm trees. Critical Review in Plant Sciences, Amsterdan, v. 19, n. 3, p. 227-247, 2000.

ROESCH, L. F. W.; OLIVARES, F. L.; PASSAGLIA, L. P. M.; SELBACH, P. A.; SÁ, E. L. S de; CAMARGO, F. A. O. Characterization of diazotrophic bacteria associated with maize: effect of plant genotype, ontogeny and nitrogen-supply. World Journal of Microbiology \& Biotechnology, Dordrecht, v. 22, n. 9, p. 967-974, 2006.

SANGOI, L.; ERNANI, P. R.; SILVA, P. R. F. da. Maize response to nitrogen fertilization timing in two tillage systems in a soil with high organic matter. Revista Brasileira de Ciência do Solo, Viçosa, MG, v. 31, n. 3, p. 507-517, 2007.

SAUBIDET, M. I.; FATTA, N.; BARNEIX, A. J. The effect of inoculation with Azospirillum brasilense on growth and nitrogen utilization by wheat plants. Plant and Soil, Netherlands, v. 245, n. 2, p. 215-222, 2002. 